\title{
Inquiry-based Learning and its Possibilities for Primary Schools with fewer Digital Resources - A Qualitative Study
}

\author{
Manuela Heindl 1 \\ ${ }^{1}$ Technical University Dresden, Weberplatz 5, 01217 Dresden, GERMANY \\ *Corresponding Author: manuela@theheindls.com \\ Citation: Heindl, M. (2018). Inquiry-based Learning and its Possibilities for Primary Schools with fewer \\ Digital Resources - A Qualitative Study. Pedagogical Research, 3(3), 12. https://doi.org/10.20897/pr/3932
}

Published: October 31, 2018

\begin{abstract}
Although there is evidence of an improvement in students' learning achievements in inquiry-based learning sessions compared to traditional lessons, the influence of technology and its possibilities for poorlyequipped schools, needs to be analysed. The research question was, 'Which effective practices emerge when students use digital, as opposed to analogue, technology in an inquiry-based learning setting?' To investigate this, a treatment group used digital technology and the control group used worksheets instead, to solve a scientific architectural problem in the creative subject 'arts and crafts'. Students were observed and teachers were interviewed. The study concludes that there is no disadvantage for primary school-aged children with access to few digital technologies. The same is true for rural and disadvantaged areas. The paper concludes, based on viewing these practices, that using digital technologies in inquiry-based learning can be beneficial for working independently, for being involved actively and for boosting a discussion when researching.
\end{abstract}

Keywords: poorly-equipped schools, inquiry-based learning, digital technologies, primary schools

\section{INTRODUCTION}

Compared with leading countries in the EU Austria's Digital Economy and Society Index is on 8 out of 28 for integration of digital technology. Measures are being planned such as teaching digital skills to school pupils and basic IT knowledge at primary schools, reinforcing the use of innovative educational technologies and optimising the framework for the use of technology at school sites by increasing its availability. Nevertheless, schools are lacking of availability of digital tools at present (Federal Ministry of Science, Research and Economy, 2016). One of the challenges for today's schools is the need to prepare students for tomorrow's work environment (Mancabelli and Richardson, 2012). Teachers are aware that they need to help students think innovatively and be prepared to compete in a high-tech workplace. This is difficult to accomplish when schools lack digital resources, which are a common tool at work. Nevertheless, even where these resources are available, teachers do not always maximise the use of computers in their lessons (Lundal and Howell, 2000). It would seem that their students are disadvantaged compared to those in other institutions with more frequent access to the online world. Inquirybased learning, however, has the potential to address this inequity (White et al., 1999). There are six criteria required to fulfil the concept of inquiry-based learning, which cannot all be explored to their full extent in one lesson (Reitinger, 2013). These are interest, method affirmation, experienced-based hypothesizing, authentic exploration, critical discourse and conclusion-based transfer. The second of these criteria includes the term choice, which should be considered when teaching this method as this element is the most alternative concept in traditional teaching. The usual way of teaching does not often allow for choices by or discussions amongst students. The teacher is the dominant person, who controls the speed and the method of learning (Leonhardt and Leonhardt, 2000). Therefore, cultivating the ability to make careful choices can be seen to achieve the aim of preparing students 
for a changing world. The question is, 'How does the use of digital media have an influence on the learning process and what are the emergent practices?' Inquiry-based learning is most established in science because its elements such as solving problems, testing hypotheses and researching is regarded as beneficial for acquiring scientific skills (Hammann et al., 2008). In order to carry this out, a science lesson is set in a classroom like the one that IEEE (2017) suggests. According to their preparation, the teacher needs to give students a specific goal of how much material they can use in order to build an architectural construction to withstand a specific amount of weight. Teachers should support students in developing an understanding of structural engineering and design by providing a stimulating environment and establishing a good work ethos. They should have tested and carried out similar projects beforehand. Students should collaborate, be creative, use different approaches, test and evaluate the effectiveness of their design and those of other teams, and finally, present the outcome. It is then interesting, to find out how they evaluate the influence of digital technologies on their process or outcome. It is also important to inquire into the teacher's and students' reflection upon how the use of digital technologies helped to develop emergent practices. Therefore, this research aims to address the following question:

RQ: Which effective practices emerge when students use digital, as opposed to analogue, technology in an inquiry-based learning setting?

For this research question, the following aspects were observed and noted by the teacher and the researcher: independent work, discussion and level activity. These and other terms will be clarified in the next paragraph.

\section{INQUIRY-BASED LEARNING WITH DIGITAL TOOLS}

The term traditional teaching method in this paper refers to the mostly widespread teaching method in the examined country and aligns with Gudjon's (2000) analysis. He concluded that the most prevalent activities in the classroom are teacher-centred, teacher-led, silent and task-based. They seldom involve active engagement, discussions or student-centred activities in which students organise and manage their own work independently. However, in inquiry-based learning lessons, students are active and can move around in order to fulfil their tasks. The elements he mentions of being active, working independently and discussing the topic with peers were included in the observation sheets. The inquiry-based learning is an alternative method of learning with a strong theoretical background, supported by governments in several countries. The National Science Foundation (1996) in America recommended an inquiry-based approach for the subjects of science, mathematics, engineering and technology which involve direct experience and the process of inquiry. According to Dinnerstein (2016) this method is not only suitable for schools; successful outcomes have been reported even in kindergarten. Induction, deduction, causation, sequences and methods lie at the heart of inquiry-based learning. Messner (2009) discusses the definition of inquiry-based learning and concludes that there are no clear differences between it and methods that are project-based, explorational, problem-based or student-centred. These are all included in this process, but they are not pre-requisites for inquiry-based learning to take place. Woolsey and Bellamy (1997) found that technology enables students to ask questions based on their observations, and encourages them to collaborate remotely with experts. This kind of inquiry would not have been possible without these tools. Littleton and Kerawalla (2012) analysed the process of digital inquiry-based learning in several projects with digital tools. They used the term 'orchestration' to describe the changing role of the teacher within the project. The teacher switches between passive and active roles throughout the lesson, and makes this choice visible to the learners. The students themselves control the input, the speed, the method, the aim, or even the whole lesson and can therefore benefit from the varying levels of teacher involvement. Their concern regarding how to improve the quality of the inquirybased learning lessons is not the core of this paper, but it rather seeks to investigate how digital technologies influence the learning achievement in these lessons. According to Jahnke et al. (2017, p. 1) "pedagogy has to evolve to include new uses of the technology" and so, inquiry-based learning phases, particularly those involving digital tools, need to be analysed in the next section. The term 'digital technologies' refer to all means that are digital in their functionality, such as MP3s, cameras, laptops, tablets or computers. The versatility of these devices lies in their ability to deliver an unlimited quantity of digitally represented always-accessible information (Tallon, 2008). The paper will analyse how these devices influence students' choices, learning processes and outcomes. The latter can be measured when learning becomes manifest. Inquiry-based learning offers a range of different assessments, including observations, discussions, performances, portfolios, self-assessments, self-reflections and the creation of a final product (Ontario Ministry of Education, 2010).

\section{EMERGENT PRACTICES}

The research question focusses on the investigation of emergent practice with digital technologies. By emergent, Ally (2009) means the ways in which students use these devices "spontaneously and autonomously rather than 
because they have been asked to". According to Snowden and Boone (2003), best or good practice is not a synonym for emergent practice. The term emergent is also mentioned in the Cynefin framework. The Welsh word stands for habitat and it was originally used to help managers to make difficult decisions. The Cynefin framework is divided into four sections: emergent, novel, good and best practice. The latter two have a cause-and-effect relationship. In best practise, the hoped for results are defined and planned for. If there are multiple ways to achieve the same results, an expert is sometimes required to recommend the best method; this is labelled good practice. In the emergent and novel practice, cause-and-effect relationships are not fixed, and it is difficult to draw up a plan for a specific outcome. Novel thinking can help to increase a teacher's willingness to experiment or tackle problems creatively as it broadens the range of options. Teachers can identify patterns that hinder results in a complex situation, which can then be avoided. They can also encourage methods that stimulate useful patterns to emerge in the system. If solutions are imposed from the outside, they might not be as effective as solutions that emerge. The consequences for pedagogical fieldwork of the solution being imposed from the outside are that the teacher has predicted an outcome (i.e. good practice) and then becomes disappointed if that outcome does not emerge. The teacher needs to be open to a local and individual solution based on the current capacities and capabilities of the student. The research paper will investigate what methods of using digital technologies are most successful in poorly-equipped schools.

\section{METHOD}

In order to answer the research question a qualitative approach will be used. To draft an emergent framework, it is advised to analyse the structured observation sheet and the recorded student interaction using the Grounded Theory (Strauss and Corbin, 1996) for the interpretation of the data. Overall, 21 Austrian primary school children of 9-10 years of age (51\% female, $49 \%$ male) participated in the study. Teachers were given an introduction to inquiry-based learning and a pre-planned lesson that ensured comparable results between different groups. The lesson focussed on how to build a bridge and was adapted from a guidebook for inquiry-based learning lessons for science in primary schools (Feige et al., 2011). The control group were given a standard worksheet explaining various methods of bridge construction. The treatment group had access to digital media to investigate how they could construct a bridge. A successful outcome was described as a construct out of paper that linked two objects and did not break when carrying the design load of 500g. Each group was taught the same lesson. One poorlyequipped class consisting of 21 students, was observed over $70 \mathrm{~min}$. The researcher served as a 'complete observer' and the teacher served as an 'observer as participant' (DeWalt and DeWalt, 2010). The structured observation sheet was comprised of Gudjon's (2000) criteria such as how actively involved are the participants, can they work independently and do they discuss the topic with peers. These three items could be rated from 1 (passive students, students need teacher's help and no discussion) to 3 (active involvement, independent work and discussion). Each of them were rated individually during Reitinger's (2013) phases and criteria: interest, method affirmation, experienced-based hypothesizing, authentic exploration, critical discourse and conclusion-based transfer for digital and offline groups separately. They will be described in the findings from a practical teaching point of view. This exploratory case study was carried out from a socio-cultural perspective. An inductive approach was chosen because there are no guided interview questions as the interviewees are too young. First, the verbal conversation during the lesson between the students was recorded and transcribed. Second, the quotes of the transcript were coded or linked to the three assessment criteria of the observation sheet. They support the observation sheet and are presented to each phase of inquiry-based learning. Then emergent practices, which occurred during the lesson, are summarised (Strauss and Corbin, 1996). In the citations, the digital groups will be assigned the code D and the offline groups, the code $\mathrm{O}$. The number 1 or 2 after the letter $\mathrm{D}$ or $\mathrm{O}$ refers to the first or the second group and the small letter afterwards refers to the individual student in the group. For the reproducibility of the study, the same pre-planned lesson and the observation sheet with the three assessment criteria has to be used to ensure validity. Research ethics has to be applied as it was realised in this paper. All pupils and parents were informed about the project beforehand. The process is anonymous and voluntarily. Teachers were given an introduction on how to prepare the lesson. When the lesson started, the teacher introduced the new topic in five minutes to the students. A handout and an information consent were given to their parents. The teacher told them that the little fluffy toy on one chair wanted to get to his friends on the other chair and the students should build a bridge with a couple sheets of paper, a glue, a sticky tape and a pair of scissors for it. This was the first phase of the inquirybased learning circle, which is called interest, where students got motivated. Two groups of three students used digital technologies, whereas the other two groups of three were given worksheets about architectural ideas of real bridges. 


\section{Outcome}

There was an equal distribution of girls and boys amongst the 21 participants (51\% female, 49\% male); the control and treatment groups also had an equal number of participants.

The researcher and the class teacher observed students during the experimental phase when they were using analogue and digital tools and recorded their conversations.

The research question was, "Which effective practices emerge when students use digital, as opposed to analogue, technology in an inquiry-based learning setting?'

To answer this research question, the observer and the researcher filled in an observer sheet, which is shown in Table 1. They rated the offline and the online groups as to how independently they were working ( 3 indicating complete independence while 1 indicated that help was needed from the teacher), if there was any discussion between them (3 meaning there was a discussion while 1 meant there was no discussion) and how active they were (3 for active, 1 for passive) during the six phases of inquiry-based learning (Reitinger, 2013). The two independent persons of raters, the teacher and the researcher, agreed overall on their observation; they achieved a Cohen's kappa of $.773(\mathrm{p}=0.0)$, which is the proportion of agreement over and above chance agreement.

\section{The Setting}

The setting can be described as the following: The problem of the poorly-equipped classroom was overcome by introducing inquiry-based learning in groups and also by the teacher's suggestion that students should be assigned a specific time online. When asked why there is only one laptop in the classroom, the head teacher said that the government cannot justify awarding more to such a small school where classes are put together to make a full class size. The parents didn't debate this issue. Before teaching, the teacher made sure that the laptop worked and was connected to the internet. Although it took several seconds to load a web page, students were quite happy using it and did not complain. There were only two students who mentioned that their computer at home was faster in loading pages. Asked what digital equipment they had at home, half of the class answered that they have internet access at home but no personal digital tool. They share it with their parents and use it only to look up homework-related issues. Other students answered that they chat, watch films, tutorials, music videos and one stated that he could also programme. The other half of the class do not have any internet access at home and use the school laptop. When asked about how they use it, they said that they would not want to use it for personal issues because they would not dare do anything personal in class. In their break, they prefer to play a board game with each other, eat their lunch or mostly chat to others. This is congruent with what has been observed. To give each student the chance to work on the one laptop, a pupil would have to adhere to a 3-minute interval in a 50minute lesson with an average of fifteen students in a class. Therefore, the teacher suggested that students should work in groups of three on it, with one typing (typist), one spotting buttons or where to click on the page (coordinator) and one responsible for the offline paperwork or for taking notes (note-taker). They were quite efficient as a group and completed tasks more quickly than if they were working alone, because they were used to that format. It was also observed that the teacher did not interfere in their students' work unless some questions arose. This is normal in inquiry-based learning when students are focussed and on track. The teacher described her computer skills as poor but her ability was sufficient to carry out this project. Therefore, the teacher felt that there was no need to integrate more advanced educational tools, which might have pushed her to improve her own digital competencies. Even though she knew that she herself was unable to embrace social media, apps or any programmes, she was aware of its future importance for the students. That is why she calls on the help of an expert when necessary. This reflects a general trend amongst teachers. It also indicates the need for more professional development in this area. As this teacher said to her students "how can I show you what to do online if I do not have neither the tools nor the experience" (T, L. 45). An overview of the findings can be found in Table 1.

In the next paragraphs, the outcomes in Table 1 are supported by the quotes of the students when being observed during the lesson. The titles referring to the level of independence, activeness and interaction will be fully described in each phase of the lesson and should explain Table 1 in more detail. The titles show the five categories for emergent practices, which were found during the coding process.

\section{Emergent Practises: 'Small Groups, Allocated Task, Homepage and Timer'}

When the lesson started, the teacher introduced the new topic, i.e. inquiry-based learning, to the students in five minutes. The teacher told them that the little fluffy toy wanted to get to his friends on the other side of the chair and the pupils should build a bridge with a couple sheets of paper, glue, tape and a pair of scissors. This first phase of the inquiry-based learning circle, which is called interest, is where students get motivated. Two 'offline groups' of three learners were given worksheets about architectural ideas drawn from real bridges, whereas two 'online groups' of three pupils used digital technologies. 
Table 1. Observer Sheet and Rating

\begin{tabular}{|c|c|c|c|c|c|c|c|}
\hline Digital Groups & $\mathbf{I}$ & D & $\mathbf{A}$ & Offline Groups & I & $\mathbf{D}$ & $\mathbf{A}$ \\
\hline Interest & 3 & 2 & 3 & Interest & 3 & 2 & 3 \\
\hline Method & 2 & 1 & 3 & Method & 1 & 3 & $1 / 2$ \\
\hline Hypothesizing & 1 & 1 & 1 & Hypothesizing & $1 / 2$ & 1 & 1 \\
\hline Exploration & 1 & 1 & 1 & Exploration & $1 / 3$ & $2 / 3$ & 3 \\
\hline Discourse & 1 & 1 & 1 & Discourse & 1 & 1 & 1 \\
\hline Transfer & 1 & 1 & 1 & Transfer & 1 & 1 & 1 \\
\hline
\end{tabular}

Summary: digital groups were more interactive, discussed more and were more active (further descriptive details in the phases below)

If there was a disagreement, both numbers are shown by the two raters (first: teacher, second: researcher)

I (independent work): 1 = work is managed and led by student, $2=$ mixed, $3=$ teacher needs to help students managing work

$\mathrm{D}$ (discussion/interaction): $1=$ all students are discussing the topic, $2=$ some students are discussing, $3=$ no discussions

A (active role): 1 = students are active $/$ move, $2=$ mixed, $3=$ students are consumers $(\mathrm{eg}$ watching $/ \mathrm{reading})$

The emergent practices found in this phase resulted from the choice of how to set up the lesson: a maximum of four participants were allocated to each group; each learner in a group had a specific task to do and was either the typist, the note-taker or the coordinator; there was a timer next to the laptop; their homepage was the search engine.

\section{The Level of Independence}

The next phase I called method affirmation which confirms the choice of how to perform the experiment. The students were asked beforehand, if they wanted to use the laptop; only those with a laptop at home and who, therefore, had more experience, wanted to be in the groups using digital technologies. The first group on the laptop was efficient and solved their problem quickly, whereas the second group deliberated for fifteen minutes and argued over the problem. The observation of this small case study shows that students who used the computer worked more quickly, cooperatively and successfully. This is visible in the statements taken while they were working: "Key in 'paper' and 'bridge' (into the web search engine)" (D1c, L.2); "This is so easy, we will have finished this so quickly"(D1n, L.3); "don't write it down, let's get the experiment done and write our ideas on paper later" (D1c, L.4); "key in 'types of bridges' (into the web search engine)" (D2c, L.5); "that's not what we want, but I will make a note, it might be useful" (D2n, L.5); "Can you go back? I think, we need that!” (D2c, L.6); "You see! This is how we will do it, we will change it a bit (to suit our needs)" (D2c, L7). These statements were recorded while they were working on the laptop. The digital tool was not used as a worksheet or a textbook, but as a means to create a solution to the given problem, to research ideas related to the problem and to explore this architectural topic. Nothing could be noted down by the other offline groups, because they were reading their worksheets silently for 10 minutes. The offline and the digital groups differed most obviously in this phase, as the digital groups obtained higher scores in being more independent when working, in discussing topics with their peers and in active involvement, than the offline groups. This can be seen in the previous observer sheet in Table 1.

The next phase focussed on formulating the hypotheses. According to what the students have read online or offline, they tried to marry the new ideas to what they already knew. One offline and all the online groups stated that folding paper was a way to make the bridge stronger.

\section{The Level of Activeness and Interaction}

During the explorational phase, the second offline group predicted, using paper, that the bridge might be stable. A recording of the discussion in the offline groups suggested anxiety and disorganisation: "So, what are we going to do?" (O2b, L. 8); "We should do something, we had better start; look at the other groups, they have already started!" (O2a, L. 9); "You see the bridge is not flat, we have to make it round, we could fold it" (O1c, L. 11); "I don't know what to do, shall we read it again?" (O2b, L.12); "No, we don't have time for that! We need to do something and do it quickly" (O2a, L.13) and "I don't know what they are doing so secretly behind their folders. So what shall we do now?" (O2c, L. 14). During that phase, the digital groups were smiling while they pre-tested their outcome and they awarded their projects the grades of B and C. The first offline group was in doubt about their success, saying "I am not sure, if this works, when we put that heavy bottle on top" (O1, L. 17). But they graded their work as A, as successful. The second offline group graded their work as B, as quite successful, but were a bit disappointed. One of them said, “This doesn't work. I don't think it will work. We need more paper and definitely a lot more glue" (O2a, L. 18), which was supported by another team member: "Yes, and more paper, a lot more paper!" (O2c, L. 19).

When testing, they saw that only the online groups were successful because the group that was working offline created a bridge which was not very stable but the bridge created by the online group could withstand a $500 \mathrm{ml}$ bottle of water easily. One offline group did not succeed because their folding technique was not efficient and the bridge of the other offline group bent to the floor. 
Table 2. Overview between offline and online groups

\begin{tabular}{|c|c|c|c|}
\hline \multicolumn{2}{|c|}{ OFFLINE } & \multicolumn{2}{|c|}{ ONLINE } \\
\hline \multirow{2}{*}{$\begin{array}{l}\text { Group O1 } \\
\text { not quite successful, bridge } \\
\text { broke }\end{array}$} & Group $\mathrm{O} 2$ & Group D1 & Group D2 \\
\hline & $\begin{array}{l}\text { not successful, bridge bent to } \\
\text { the floor }\end{array}$ & $\begin{array}{l}\text { successful bridge can hold } \\
\text { more than } 500 \mathrm{ml}\end{array}$ & $\begin{array}{l}\text { successful bridge can hold up to } \\
500 \mathrm{ml}\end{array}$ \\
\hline \multicolumn{2}{|c|}{$\begin{array}{l}\text { stressful, teacher had to help more, less discussion, passive } \\
\text { while reading }\end{array}$} & \multicolumn{2}{|c|}{$\begin{array}{l}\text { less stressed, a higher level of independent work, discussing topics } \\
\text { with peers, active involvement }\end{array}$} \\
\hline \multicolumn{4}{|c|}{ Emergent practices for online groups: } \\
\hline \multicolumn{4}{|c|}{ groups of $3-4$} \\
\hline \multicolumn{4}{|c|}{ allocated task (typist, note-taker, coordinator) } \\
\hline \multicolumn{4}{|c|}{ hardware, Wi-Fi and software check } \\
\hline \multicolumn{4}{|c|}{ web-search engine as starting web-page } \\
\hline \multicolumn{4}{|c|}{ timer next to the laptop efficient time on laptop (help from the teacher might be required) } \\
\hline
\end{tabular}

\section{Emergent Practice: 'Use Time Efficiently'}

After that, the groups discussed their results in a discussion round. One student of the group that failed the experiment started the discussion by saying "I was thinking, if we were given more time, more paper and more glue, we would have succeeded, but that's not true. Anyway it was a lot of fun!'(O2c, L.24). They all agreed that it was a great experiment by saying: "Can we also learn in other subjects like that? I mean about the nature and the earth. Can we do more experiments?" (O1c, L. 26); "Yes, that was so cool; we didn't win, but..." (O2c, L. 27); "It's not about winning, you were good too!" (O1c, L.28) and "I know, but we were somehow lost, we needed another idea. Ours would have never worked! I think I would like to use the laptop next time!" (O2c, L. 30). The students also commented on how to use the laptop: "We were using the laptop, but it was not as easy as you think. We didn't look at the screen and got the answer presented to us!" (D2a, L. 32); "I know, it's not as easy as that, but you could get an idea, a quick look would have helped" (O2a, L. 33); "Yes, maybe, but if you use it longer than that, it doesn't help you more" (D2a, L. 34); "Yes, I agree with D2a, either you see it immediately what you need or you leave it" (O2a, L. 35) and "I think you need to type in the right words" (O1t, L. 36). From this we can see that a longer session on the laptop did not lead to a more successful outcome. This paper's findings promote the idea that poorly-equipped schools can implement inquiry-based learning with digital tools and these lessons can result in successful student achievements.

The emergent practice found in this phase was that the students had to use their online time efficiently. Both groups had the same amount of time on the laptop. However, one group was more successful than the other group because the learners typed more topic-related words into the search engine. If there are only a few digital tools available, it might be useful to assist young learners during the research phase to find the requested online pages more quickly. This could be explained in an introduction on how to use search engines efficiently, including how to pinpoint effective cues. This would help the students make better use of their time.

\section{The Ending of the Project}

In the last so-called transfer phase, they all presented their work to the other school classes. The groups talked freely about their success or why experiments failed and were given the choice to create the presentation themselves. An overview for the findings will be given in Table 2 and the following summary.

In brief, inquiry-based learning with digital tools can be very beneficial for poorly equipped schools, if they discuss their outcomes and process work with the peers, to develop emergent practice with their teacher. Similar to this research, it can lead to the following evident findings. Both, the researcher's and the teacher's notes agreed on the following statements distinguishing between the control and the treatment group: The online groups were working quite quickly, and goal orientated, whereas the one offline group seemed stressed as their hypothesis turned out not to be successful and every attempt to improve their construction failed. They wanted to be given more time to stick even more paper together. In the discourse phase, they realised that even more time would not have solved their problem. They were so fixed on their idea, that they were not open to other suggestions. They said that the laptop might have given them other ideas, though the worksheets were useful, but did not include everything they needed to be successful. There was not much speech recorded, because in general, there was a working atmosphere in the classroom. The students were busy with their work and very dedicated. The findings in this small case study show that students with digital technologies were quicker in their decision-making, had a broader view on the topic or allowed other ideas to influence their process had a correct hypothesis and a successful outcome. The researcher's and the teacher's notes did not agree on the following: The teacher described the offline groups as being less independent less communicative and less active than the researcher in three phases. There was no disagreement between the observers in rating the digital groups. 


\section{Summary of the Emergent Practices and the Observation Sheet:}

The observation sheet reveals that the level of interaction, discussion and the interaction between students in the digital groups is higher than in the groups without these tools. Therefore, digital tools support the elements of inquiry-based learning. The aim in this paper was to emerge practices for schools with few digital resources and is summarised here.

First, teachers need to organise their project time efficiently and put the children into groups of three or four. Second, every student has a role in front of the laptop and this should switch, so that everyone has the chance to be either the coordinator, the note-taker or the typist. Third, the teacher needs to make sure that the equipment works before the start of the lesson. Fourth, the teacher has a web-search engine as their starting web page, so that it can load in the meantime. Fifth, the time in front of the laptop has to be timed and students need a reminder to know how much time they have left. Sixth, computer skills are not a precondition to produce a successful outcome, according to students' views how the time is used on the laptop is more important. Digital technologies change the way of learning during students' research when inquiry-based learning. They can contribute to reach a higher level of independence when working and active involvement. Furthermore, students tend to discuss their topic with peers when researching and they seem less stressed.

\section{DISCUSSION}

Before addressing the interpretation of the findings, certain aspects of this study need to be considered which are the small number of participants and the age of the learners in primary school. Furthermore, these students had had little experience of inquiry-based learning. The observation sheet catalogues the observers' comments. Technical equipment is not always present in the classrooms due to lack of finances or governmental regulations. The goal of inquiry-based learning is to find ways to teach students to become independent learners at school. This study shows that using digital tools leads to a positive change in the classroom dynamic. However this paper demonstrates that there is a need for care when implementing new technology in the classroom; in fact, it is much more effective if the use of digital tools emerges naturally. Therefore, teachers need to find a way to build on existing facilities. This aligns with Howland et al.'s (2011) conclusion that technology cannot teach students, but they can learn as they use technology. Two of their conclusion points pertained to conversation and collaboration, which was rated on the observation sheet. In this study, these two aspects came out ahead in the digital groups. Furthermore, the digital groups in this study were more active and interactive just as observed by Jayawardana et al. (2001). They were reporting on activities such as active reading, active watching and active listening. Additionally, the students in this study learnt through interaction with other students. This paper shows how seeming disadvantages, especially the lack of digital equipment, can be dealt with by adjusting the structure of the lesson. Emergent practises that worked observed by this paper were putting the students into smaller groups, allocating tasks, checking the Wi-Fi on laptops, using the web-search engine as the starting web page and using a timer. The findings align with the study of Armbruster et al. (2009) that suggested that not more than four students should be in a problem-solving group that each student should have an allocated task within the group and that 35 minutes is enough time for the research. The outcomes of this paper are congruent with Rubagiza et al. (2011) who stress the importance of dependable equipment.

These practices provide an opportunity for students in rural areas or attending poorly-equipped schools, to gain the skills to adapt to a vastly different setting in their future workplace.

\section{ACKNOWLEDGEMENTS}

I would like to thank Mayda Narvey for her help in editing this paper. Her guidance assisted me throughout the research and writing of this thesis. I could not have imagined having a better advisor and mentor.

\section{REFERENCES}

Armbruster, P., Patel, M., Johnson E. and Weiss, M. (2009). Active learning and student-centred pedagogy improve student attitudes and performance in introductory biology. CBE, 8(3), 203-213.

DeWalt, K. M. and DeWalt, B. R. (2011). Participant observation. Maryland: Rowman \& Littlefield.

Dinnerstein, R. (2016). Choice Time. Portsmouth: Heinemann.

Faul, F., Erdfelder, E., Lang, A.-G. and Buchner, A. (2007). G*Power 3. Behavior Research Methods, 39, 175-191. https://doi.org/10.3758/BF03193146 
Federal Ministry of Science, Research and Economy (2016). Digital Roadmap. Vienna. Available at: https://www.digitalroadmap.gv.at/fileadmin/downloads/digital_road_map_broschuere_eng.pdf (Accessed 20 May 2018)

Feige, C., Hünerfeld, K., Kaya, S., Knorke, A., Langhorst, F. and Thate, S. (2011). Prima(r)forscher. Berlin: Spreedruck. Available at: https://www.telekomstiftung.de/sites/default/files/files/media/publications/broschuere_primarforscher_web.pdf (Accessed 17 August 2017)

Gudjons, H. (2000). Handlungsorientiert lehren und lernen. Bad Heilbrunn: Julius Klinghardt.

Hammann, M., Phan, T. H. and Bayrhuber, H. (2008). Experimentieren als Problemlösen. In Kompetenzdiagnostik (pp. 33-49). Wiesbaden: VS Verlag für Sozialwissenschaften. https:// doi.org/10.1007/978-3-531-90865-6_3

Howland, J. L., Jonassen, D. H. and Marra, R. M. (2011). Goal of Technology Integrations. In J. L. Howland (Ed.) (4th ed., pp. 1-19). Essex: Available at: https://www.pearsonhighered.com/assets/samplechapter/0/1/3/2/0132565587.pdf

IEEE. (2017). TryEngineering. Available at: http://tryengineering.org/lessons/popsiclebridge.pdf (Accessed 10 October 2017)

Jahnke, I., Bergström, P., Marrell-Olsson, E., Häll, L. and Kumar, S. (2017). Digital Didactical Designs as research framework. Computers \& Education, 113, 1-15. https://doi.org/10.1016/j.compedu.2017.05.006

Jayawardana, C., Prizanatha, K. and Hirakawa, M. (2001). Personalization tools for active learning in digital libraries. $M C, 8(1)$.

Leonhardt, M-M. J. and Leonhardt, R. (2000). Unterrichtsformen konkret. Zug: Klett und Balmer.

Littleton, K. and Kerawalla, L. (2012). Trajectories of inquiry learning. In K. Littleton, E. Scanlon \& M. Sharples (Eds.), Orchestrating Inquiry Learning (pp. 31-47). Chippenham: CPI Antony Rowe. https://doi.org/10.4324/9780203136195

Lundal, P. and Howell, C. (2000). Computers in Schools. University of the Western Cape, South Africa. Available at: https://www.education.gov.za/Portals/0/DoE\%20Branches/FET/Curriculum\%20Innovation/ICT\%20Au dit.pde?ver=2008-03-05-111213-000 (Accessed 31 August 2017)

Messner, R. (2009). Forschendes Lernen aus pädagogischer Sicht. In Rudolf Messner (Ed.), Schule forscht (pp. 1530). Hamburg: Ed. Köber-Stiftung.

National Science Foundation. (1996). Arctic Research of the United States. 10, 2-8. Available at: https:/ /www.sciencebase.gov/catalog/item/50577e27e4b01ad7e027ec49 (Accessed 20 August 2017)

Ontario Ministry of Education. (2011). F Growing Success. Assessment, Evaluation, and Reporting in Ontatrio Schools. Available at: http://www.edu.gov.on.ca/eng/policyfunding/growSuccess.pdf (Accessed 31 August 2017)

R. (2008). R: R Foundation for Statistical Computing, Vienna, Austria. Available at: http://www.R-project.org. https://cran.r-project.org/web/packages/compute.es/compute.es.pdf (Accessed 18 August 2017)

Reitinger, J. (2013). Forschendes Lernen. Immenhausen bei Kassel: Prolog-Verlag Reihe.

Richardson, W. and Mancabelli, R. (2012). Personal Learning Networks (3rd ed.). Bloomington, IN: Solution Tree Press.

Rubagiza, J., Were, E. and Sutherland, R. (2011). Introducing ICT into Schools in Rwanda. IJED, 31(1), 37-43.

Strauss, A. L. and Corbin, J. M. (1996). Grounded theory: Grundlagen qualitativer Sozialforschung. Weinheim: Beltz.

Tallon, L. (2008). Digital Technologies and the Museum Experience. AltaMira: Plymouth.

White, B. Y., Shimoda, T. A. and Frederiksen, J. R. (1999). Enabling students to construct theories of collaborative inquiry and reflective learning. International Journal of Artificial Intelligence in Education, 10, 151-182.

Woolsey, K. and Bellamy, R. (1997). Science education and technology. The Elementary School Journal, 97(4), 385399. https://doi.org/10.1086/461872

\section{REFERENCES FOR INTERVIEWEES}

Teacher. (2017). Teacher of the examined school.

D1n, D1c, D1t, D2n, D2c, D2t, O1a, O1b, O1c, O2a, O2b and O2c. (2017). Pupils of the examined school. 